\title{
Global Governance and Innovation 2020: how to Govern the Complexities of the Future
}

\author{
Giorgio Dominese
}

Published online: 22 April 2009

(C) Springer-Verlag 2009

In the past two years, many warnings had been launched by the scientific community and global governance experts on the extremely dangerous and unpredictable earthquake consequences, which was showing its first premonitory shock waves, in the economic, financial and political international order. In Spring 2008, at Shanghai University, the Dean of the School of International Relations, Yu Chen Sang, and the Dean of the Faculty of Economics of Rome Tor Vergata University, Michele Bagella, representing the Rector, signed an agreement to launch the second edition of the Youth Innovation Competition on Global Governance (YICGG), inviting me to coordinate the research program and the two conclusive weeks in Rome. I had in mind to focus the research of the young participants and the lectures delivered by professors and experts against the backdrop of the economic, financial and political crisis which in the meantime had erupted.

It was neither the year 1929, which many "guardians" of the past hastily tried to evoke, nor the periodic negative cycle of 1999 or the regional financial crises witnessed in the last decades, especially after 1989. Every speculation or search for comforting parallel developments has been crushed by the crude reality. And so the title of the 2008 edition of the Research Competition "Global Governance and Innovation 2020" was found appropriate. This concept will be maintained as an introduction title to future editions, starting from the imminent 2009 event.

The impending change of the international order and the main players and factors determining policies and strategic choices, which once was an absolute monopoly of nation-states, empires and hegemonies, has shown itself with the dawn of a planetary era. It will be a very engaging age because it will require acceptance of the

\footnotetext{
G. Dominese $(\bowtie)$

Faculty of Economics, Tor Vergata University, Rome, Italy

e-mail: giorgio.dominese@uniroma2.it; giorgio.dominese@ceeun.org

G. Dominese

Coordinator Transition World Research Network, Venice, Italy
} 
principle of challenging and critically reviewing, adapting social, political, ethnic, identities but first and foremost scientific and cultural assumptions and theories now until the international community is brought a whole a kind of comfort, of certitudes, of simplified policies. There will be no way out if we want to avoid the complete destruction of mankind, and thus we have to fully exploit the sophisticated and forecasting theories and the infinite capacity of quantitative processing provided by the electronic and informatics revolution, going beyond the "two prisoners dilemma" various assumption and application and becoming the multipolar, polyedric approach of "many prisoners dilemma". It is quite a demanding age, requiring change and effective solutions without any easy bridging way out if not at the concrete risk of a tremendous holocaust of entire humanity. We have to accept discussing and openly confronting the principle of arguing and critically reviewing the already asymmetric social, political, ethical values, but principally the strong scientific and cultural beliefs and traditions of the whole international community. This does not mean we have to renounce eternal values, the "identity and diversity" that make up the universal intellectual and spiritual heritage, the ethic and moral values of a varieties of philosophic and religious faiths.

This attitude and mental mindset should be presented and taught to the individual citizen but beforehand and immediately it requires leadership, elites, knowledge, competence, investments, reforms, resources and permanent innovation based on cultural and technological emergences, the environmental and energetic priorities which are continually evolving and sweeping away yesterday's experience of mankind and society. Never before this historic period of passage has the indispensable need for an architecture of international governance-as the European Union has been able to show in the 60 years since its foundation-been so strongly felt. This is a convergent interpretation of the complexity of the future evoked 15 years earlier by the French philosopher Edgar Morin in his famous essays "How to govern the future complexities" and "Seven Complex Lessons in Education for the Future".

But what does YICGG mean, and which are the aims and scope of the program? As we mentioned in the introductory remarks, during the second Edition in Rome, which took place from 18 August to 26 August 2008 at Tor Vergata University and the Casa dell'Aviatore, in close cooperation with the Italian Air Force which gave logistics and accommodation support. The Research Competition Youth Innovation Competition in Global Governance (YICGG) had been promoted in 2007 by Fudan University (http://www.cgg.fudan.edu.cn), sponsored by United Nations Development Programme (UNDP) in China and organized by the School of International Relations and Public Affairs (SIRPA) of Fudan University. Since October 2007 and following the Memorandum of Understanding in March 2008, a new partnership has been founded to promote on a regular yearly basis the 2008 edition and the future editions until 2011 with top ranking Italian Institutions. These include the prestigious Rome Tor Vergata University, School of Economics, with its Centre Economic International Studies (CEIS); the Politecnico of Turin; Transition World Research Network-CEEUN, based at Ca' Foscari University Venice, which is in charge of the coordination, diffusion, participation in the YICGG 2008 program and the selection of a number of faculty and students among its almost 500 partners in 
the world. It must be mentioned that a new Europe-Asia partnership has been launched in the framework of the Eastern Asia Special Program of the School of Economics of Rome Tor Vergata University which at present provides cooperation with a number of universities in China, South Korea, Japan, Viet Nam and Singapore.

The YICGG is open to university postgraduate and doctoral students from all around the world. Participants in the 2008 2nd Edition in Rome have been postgraduate and doctoral students from the three Universities and many other worldwide universities and research centers, as you can read in the next introductory document summarizing the conclusion of the Research Competition, its participants, the prize-winning research and all the papers submitted by groups or individual junior researchers. All the faculty, supervisors and selected students were granted free accommodation in Rome.

As we wrote in the preparatory document: "With the deepening of globalization we live in a world with more efficient transnational interactions, an increasingly interdependent global market, an accelerating process of regional integration and global cooperation. Meanwhile, many global issues have also emerged as our common concerns. These include global growth and development, international governance of economic, financial, security, multilateral organizations, human capital and higher education, new technologies and innovation specifically in the most advanced industrial sectors as aerospace and car manufacturing, global warming, alternative energy, environmental degradation, cultural heritage management, global poverty and refugees, diseases and infection diffusion, transnational crimes and terrorist threats, food and water production and supply as crucial factors of development, just to indicate some more relevant factors".

"Every citizen with in the global society" — continues the document- "has the responsibility to explore the management of global interdependence and to tackle these challenges. As future leaders and constructors of human society, youth students all around the world should bring our creativity into full play to assume our common responsibilities. That is why the YICGG wants to become a point of reference for your junior research and creativeness in analyzing and proposing solutions to the main themes of today and tomorrow, with the future editions".

The program, which encountered a positive international response because of its specific character and the approach adopted in involving and selecting the participants, was made possible thanks to a distinguished Scientific Committee, with a Faculty of almost 30 professors from European and Asian universities, under the coordination of the signing partner universities and research centers. This innovative transnational initiative received the endorsement and support of Telecomitalia, IntesaSanpaolo, Finmeccanica, Ibm, Springer Wien, NewYork and the Ali-Art Learning Institute of Rome. The Ministry of Foreign Affairs and the Italian Embassy in Beijing gave an important contribution to make this intense international university cooperation possible.

A Judging Commission awarded a prize to the three most outstanding research papers prepared in a range of 12 thematic areas covering the most important issues challenging the world: economic growth, governance of the financial world, security, the reform of the United Nations, the future developments in the aviation 
and automobile sectors, the conservation and management of the cultural heritage, new and unhoped-for developments of technological innovation through nanotechnologies, digital applications, information and multimedia-based technology with direct and positive impacts on the quality of the environment, the progress of therapies and medical diagnosis, and the competitiveness of the global system. A special workshop will be dedicated to the relations between Asia and Europe in the long term and their implication for international "governance".

As stated in the concluding remarks by the present Rector, Renato Lauro, elected to the office soon after the Research Competition: “Tor Vergata University has asserted its position in this challenge with a long-lasting policy with important scientific results at the national and international level. Now the YICGG has fulfilled these achievements. The Faculties of Economics, Sciences, Engineering, Law, Humanities and Medicine involved their students and lecturers, in order to assure the critical mass necessary for a successful organization of the program, in which more than 100 students from Asia, and in particular China, the United States and the Middle East are participating".

We choose to award prizes to some of the research presented by the junior researchers attending YICGG 2008 in Rome and to publish them in a special issue of Transition Studies Review. In fact, we should also have published the valuable and really enlightening papers that were a kind of guideline for the contribution of more than forty distinguished Faculty and Scholars-already inserted in the web at the address www.economica.Uniroma2.it—but we decided to leave them in e-version and to focus on the junior Masters and PhDs, in agreement with the advice of the Scientific Committee. In fact, the sense of the Research Competition is really this: to emphasize the valuable contributions from the young students participating.

Nevertheless, you will find in this volume the full list of all the Faculty and students involved and we will be happy to stay in contact with them, looking to further initiatives and programs, starting with the 2009 Edition of the YICGG.

More than this, we intend to develop a closer partnership both in the research and postgraduate and doctoral higher education with Fudan University Shanghai, Rome Tor Vergata, hopefully with Politecnico di Torino, but also with a select group of others universities, schools, institutes and centers in Europe, Asia, the Americas, Mediterranean, Eurasia, the Middle East and Africa and worldwide. We are at work with a proposal that could be suitable for our aims and will to contribute to the "Global Initiative and Policy" related with Governance and Innovation. 